Check for updates

The BMJ

Cite this as: BMJ 2020;371:m4576 http://dx.doi.org/10.1136/bmj.m4576 Published: 24 November 2020

\title{
Covid-19: What do we know about the late stage vaccine candidates?
}

\section{As some phase III trials of covid-19 vaccine candidates report early and unpublished results, Elisabeth Mahase summarises what we know so far}

\section{Elisabeth Mahase}

\section{University of Oxford and AstraZeneca vaccine}

The ChAdOx1 nCoV-19 has been tested across the world, with trials starting in the UK and branching out to Brazil, South Africa, and the US. Phase II results, published in the Lancet, found that the vaccine produced a similar immune response in old and young participants. Phase III interim results, based on 131 cases, have been made available through a press release (23 November) and suggest the vaccine could be up to $90 \%$ effective when a half dose is given, followed by a full dose one month later. ${ }^{1}$ When two full doses are given one month apart, however, the effectiveness drops to $62 \%$. Sarah Gilbert-who is leading the vaccine team at the University of Oxford-said the half dose regime may be more effective because it "better mimics" a real infection. They are still, however, investigating this effect.

The UK government has agreed a deal for 100 million doses of the vaccine, which could be used to vaccinate 66 million people if the half dose plus full dose regime is followed. The Oxford team has stressed that they want their vaccine to be accessible around the world and not just high income countries. As such, large scale manufacturing has been set up in over 10 countries and the team expects the vaccine to be available at a low price-around $£_{3}\left(€_{3.4}\right.$; \$4) per dose. The vaccine can be stored at fridge temperature $\left(2-8^{\circ} \mathrm{C}\right)$.

\section{Pfizer and BioNTech vaccine}

Pfizer and BioNTech's BNT162b2 is the first vaccine candidate to be submitted to the US Food and Drug Administration (FDA) for emergency use authorisation. ${ }^{2}$ The submission was filed on 20 November, after the conclusion of a phase III trial. The results, released by press release, evaluated 170 confirmed cases of covid-19 and reported that the vaccine was $95 \%$ effective 28 days after the first dose. Nine out of 10 severe covid-19 cases in the trial were in the placebo group.

Pfizer said the vaccine could be available to high risk populations in the US by the end of December 2020. The UK government has agreed a deal for 40 million doses (enough for 20 million people) and expects to have 10 million doses by the end of 2020. Meanwhile, the EU has secured a deal for 200 million doses, with an optional 100 million extra doses. Globally, 50 million doses are expected in 2020 and up to 1.3 billion doses by the end of 2021. The companies have started submission processes in Australia, Canada, Europe, and Japan. The vaccine is estimated to cost around £15 per dose-much higher than the Oxford-AstraZeneca vaccine. Concerns have also been raised over logistics, as the vaccine must be stored at $-70^{\circ} \mathrm{C}$.

\section{Moderna and US National Institutes of Health vaccine}

The mRNA-1273 vaccine, developed by US biotech company Moderna in partnership with the US National Institutes of Health (NIH), is $94.5 \%$ effective according to the interim findings of US based phase III trial results. ${ }^{3}$ The analysis was based on 95 covid-19 cases, of which 90 ( 11 severe) were observed in the placebo group and five were reported in the vaccine group.

The trial enrolled more than 30 ooo US participants, including 7000 aged over 65 and 5000 under 65 with high risk chronic diseases. More than one third $37 \%$, 11 ooo) of the trial participants were from “communities of colour.” Of the 95 cases, 15 were adults over 65 , and 20 identified as being from diverse communities (12 Hispanic, four black, three Asian American, and one multiracial).

Moderna intends to submit the interim safety and efficacy data to the FDA for emergency use authorisation soon, following a final analysis of 151 cases and a median follow-up of more than two months. The US has agreed a deal for 100 million doses, while the UK government has secured five million doses of the vaccine candidate. If approved by the medicines regulator, the vaccine could be delivered to the UK in spring 2021.

Moderna's vaccine can be stored in a household fridge for 30 days, at room temperature for up to 12 hours, and at $-20^{\circ} \mathrm{C}$ for up to six months. However, compared with the Oxford-AstraZeneca and Pfizer vaccines, Moderna's candidate is much more expensive at approximately £25 per dose. 


\section{NEWS}

The seven vaccine developers the UK government has agreed deals with

\begin{tabular}{lccc}
\hline Name & Phase & Agreements & \multicolumn{1}{c}{ Efficacy } \\
\hline Oxford-AstraZeneca & Phase III & 100 million doses & $\begin{array}{c}\text { Up to 90\% efficacy } \\
\text { (preliminary data) }\end{array}$ \\
\hline Pfizer-BioNTech & Phase III & 40 million doses & $\begin{array}{c}95 \% \text { efficacy } \\
\text { (preliminary data) }\end{array}$ \\
\hline Moderna & Phase III & 5 million doses & $\begin{array}{c}\text { 95\% efficacy } \\
\text { (preliminary data) }\end{array}$ \\
\hline Novavax & Phase III & 60 million doses & No phase III data \\
\hline Janssen & Phase III & 30 million doses & No phase III data \\
\hline GSK-Sanofi & Phase II-III & 60 million doses & No phase III data \\
\hline Valneva & Preclinical & 60 million doses & No phase III data \\
\hline Source: UK government (information up to date as of 23 November) & \\
& & & \\
& & &
\end{tabular}

1 Mahase E. Covid-19: Oxford vaccine is up to $90 \%$ effective, interim analysis indicates. BMJ 2020;371:m4564doi: 10.1136/bmj.m4564.

2 Mahase E. Covid-19: Pfizer and BioNTech submit vaccine for US authorisation. BMJ 2020;371:m4552. doi: 10.1136/bmj.m4552 pmid: 33219049

3 Mahase E. Covid-19: Moderna vaccine is nearly 95\% effective, trial involving high risk and elderly people shows. BM/2020;371:m4471doi: 10.1136/bmi.m4471.

This article is made freely available for use in accordance with BMJ's website terms and conditions for the duration of the covid-19 pandemic or until otherwise determined by BMJ. You may use, download and print the article for any lawful, non-commercial purpose (including text and data mining) provided that all copyright notices and trade marks are retained. 